Treaty Verification Arms Control and Treaty Verification Arms Control and Trealy Verification Arms Control and Trealy Verification Arms Control and Treaty Verification Arms Control and Treaty Verification Arms Control and Treaty Verification Arms Control and Trealy Verification Arms Control and Treaty Verification Amms Control and Treaty Verification Ams Control and

Treaty Verification Arms Control and Treaty Veritication Ams Control and Treaty Verification Arns Control and trealy Verification Arms Conrol and Treaty Verification Arms Control and Treaty Verification Arms Control and Trea y Verification Arms Control and Treav Verification Amme Control and Tealy Veritication

\title{
Role of Atmospheric Corrosion of Aluminum Alloys in Viability of Intrinsic-surface Methods for Tagging Military Hardware
}

\author{
by P. S. Maiya and T. F. Kassner
}

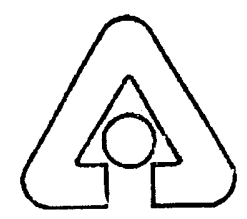

Argonne National Laboratory, Argonne, Illinois 60439

operated by The University of Chicago

for the United States Department of Energy under Contract W-31-109-Eng-38 
Argonne National Laboratory, with facilities in the states of Illinois and Idaho, is owned by the United States government, and operated by The University of Chicago under the provisions of a contract with the Department of Energy.

\section{DISCLAIMER}

This report was prepared as an account of work sponsored by an agency of the United States Government. Neither the United States Government nor any agency thereof, nor any of their employees, makes any warranty, express or implied, or assumes any legal liability or responsibility for the accuracy, completeness, or usefulness of any information, apparatus, product, or process disclosed, or represents that its use would not infringe privately owned rights. Reference herein to any specific commercial product, process, or service by trade name, trademark, manufacturer, or otherwise, does not necessarily constitute or imply its endorsement, recommendation, or favoring by the United States Government or any agency thereof. The views and opinions of authors expressed herein do not necessarily state or reflect those of the United States Government or any agency thereof.

Reproduced from the best available copy.

Available to DOE and DOE contractors from the

Office of Scientific and Technical Information

$$
\text { P.O. Box } 62
$$

Oak Ridge, TN 37831

Prices available from (615) 576-8401, FTS 626-84i)1

Available to the public from the

National Tecinnical Information Service

U.S. Department of Commerce

5285 Port Royal Road

Springficld, VA 22161 
ANL/ACTV-91/6

\section{ARGONNE NATIONAL LABORATORY \\ 9700 South Cass Avenue \\ Argonne, Illinois 60439}

\section{ROLE OF ATMOSPHERIC CORROSION OF ALUMANUM ALLOYS IN VIABAITY OF INTRINSIC-SURFACE METHODS FOR TAGGING MILITARY HARDWARE}

by

P. S. Malya and T. F. Kassner

Materials and Components Technology Division

November 1991

Work sponsored by

U. S. Department of Energy

Office of Arms Control 


\section{Contents}

Abstract.

1

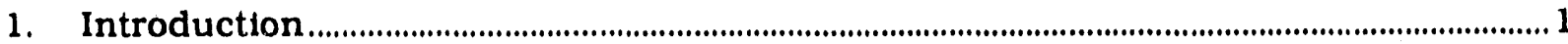

2. Characterization of Atmospheric Environments ....................................................................... 2

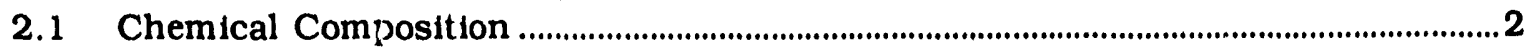

2.2 Physical Properties of the Atmosphere Important in Corrosion ................................ 4

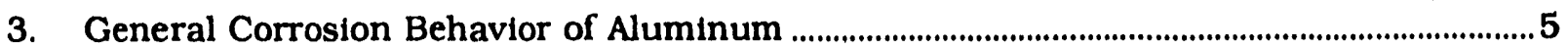

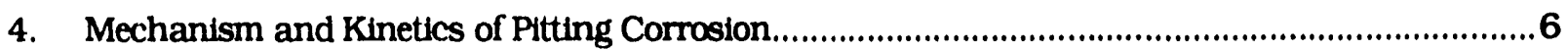

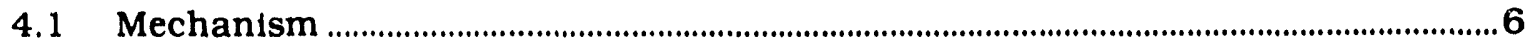

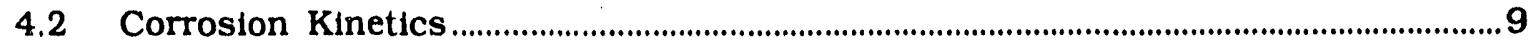

4.3 Size of Surface Topological Features in Relation to Corrosion Penetration ...........9

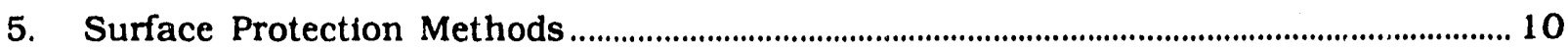

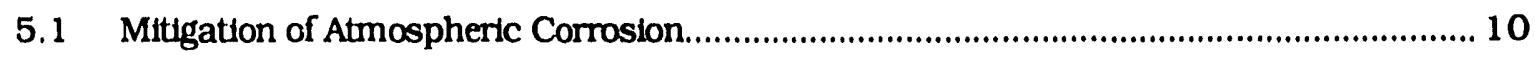

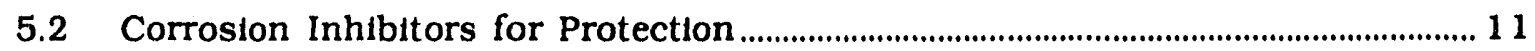

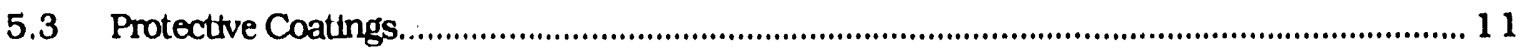

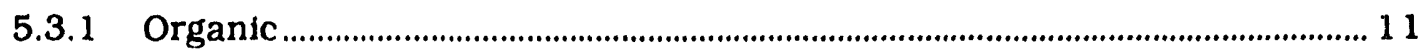

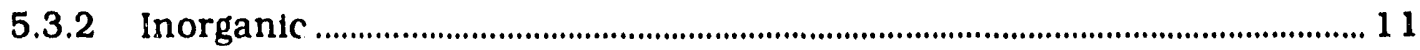

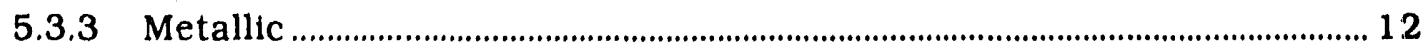

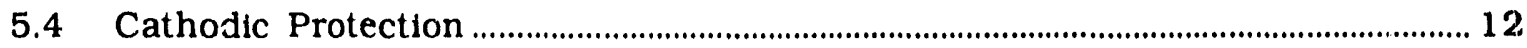

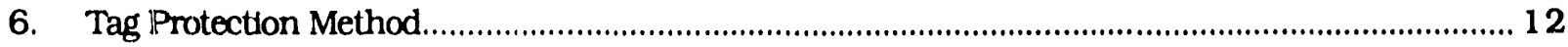

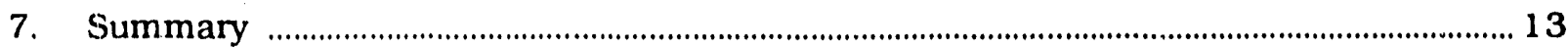

Appendix: Experimental Methods for Investigating Atmospheric Corrosion.................... 15

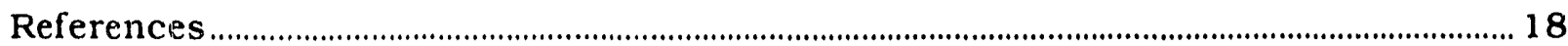




\section{Figure}

1. Potential-pH diagram for the $\mathrm{Al}-\mathrm{H}_{2} \mathrm{O}$ system at $25^{\circ} \mathrm{C}$, for concentration of $\mathrm{Al}$ spectes of $0.1 \mathrm{M}$.

\section{Table}

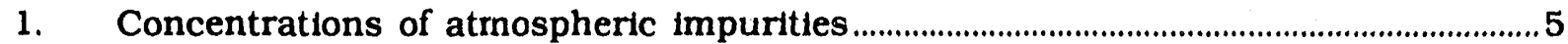




\title{
ROLE OF ATMOSPHERIC CORROSION OF ALUMINUM ALLOYS IN VIABILITY OF INTRINSIC-SURFACE METHODS FOR TAGGING MILITARY HARDWARE
}

\author{
by
}

\author{
P. S. Matya and T. F. Kassner
}

\begin{abstract}
A primary requirement for authentication of tags for military equipment designated as treaty-limited items (TLIs) is that the surface topography of the tag area be maintained after exposure to a variety of atmospheric conditions over many years. This report summarizes the chemical and physical properties of atmospheres as they relate to localized corrosion of aluminum and aluminum alloys. The role of impurity species that exacerbate corrosion, and that hence may interfere with tag verification, is discussed. Because exposure times for the tag materials are much longer than those practical in laboratory experiments, it is important to understand the kinetics of processes occurring in these alloys and the viability of various protection schemes. General principles and limitations of testing in natural atmospheres and in the laboratory are discussed. Corrosion results indicate that the tag surface must be protected, and a tag protection scheme is proposed.
\end{abstract}

\section{Introduction}

Because arms limitations do not necessarily lead to elimination of all items in a given class of weapons, on-site verification can be enhanced significantly by the use of tamperrevealing unique identifiers, commonly known as tags. Unique identification could make use of "natural" or induced intrinsic features in the surface of treaty-limited items (TLIs). 1 Intrinsic features embedded in the surface of a TLI are more secure than artificially attached tags, which have the potential of being transferred without detection. Consequently, authentication of micrometer-scale surface features by a high-resolution scanning electron microscope (SEM) is a potentially attractive method of verification.

The intrinsic-surface tag would be authenticated by comparing SEM surface images obtained in an initial baseline inspection with images obtained in a subsequent field inspection. These images could be obtained directly by attaching an SEM to the surface, or indirectly by making plastic castings that are brought to the SEM. Envircnmental degradation of the tag surface between inspections is a potential concern in authentication of TLIs with intrinsic-surface tags. Any tag, whether intrinsic or attached to the surface, could suffer problems due to atmospheric corrosion. This report focuses on likely degradation modes of topographical features and explores a method to extend tag lifetime. This is a multifaceted problem that depends on the nature and expected service life of the 
tag, corrosion resistance of the material (i.e., alloy), specific environmental conditions, resolution of the microanalytical method, and reproducibility of the results (1.e., images or data) used in the verification process. The implications of atmospheric corrosion on the viability of surface "fingerprints" as a tag, namely, natural surface features and microscopic indentations such as surface ssratches, are discussed for TLIs constructed of aluminum or aluminum-base alloys, which exhibit relatively good resistance to atmospheric corrosion or weathering. Although TLI surfaces might be made of many different metals or composite materials, aluminum has been chosen for this evaluation of tag corrosion.

Protective oxide fllms form on $\mathrm{Al}$ and its alloys upon exposure to atmospheric environments. These oxide films further react with impurities, water, and other constituents of the atmosphere, which disrupts the oxide and leads to formation of less protective corrosion products. Thus, the early stages of corrosion appear as discoloration, roughening, and pitting, depending on exposure time and severity of the environment. Corrosion, especially pitting, can alter the topographical features that are central to the intrinsic-surface tag. This review focuses on atmospheric corrosion, with emphasis on localized (pitting) corrosion. Because the literature pertaining to atmospheric corrosion is extensive, the results presented here are typical rather than comprehensive. We have drawn heavily on several review articles and relevant papers on this topic. ${ }^{2-5}$

\section{Characterization of Atmospheric Environments}

Atmospheric corrosion is an electrochemical process that involves anodic (electrondonating) and cathodic (electron-consuming) reactions and an electrolyte and ions to carry the lonic current. The electrochemical reactions are affected by the atmosphere's chemical and physical properties. 6 The various constituents of the atmosphere are described below.

\subsection{Chemical Composition}

Because atmospheric corrosion proceeds by an electrochemical mechanism, it is important to review the chemical composition of the atmosphere ${ }^{2}$ and identify the role of the various constituents in corrosion.

Nitrogen and Inert Gases: Although these constitute the majority of the atmosphere, they do not react with $\mathrm{Al}$ surfaces in typical environments.

Oxygen and Ozone: Unlike nitrogen, oxygen and ozone are important atmospheric components that have a strong influence on corrosion. Because atmospheric corrosion is an oxidation-reduction process, the metal serves as an electron donor, and the oxygen and other reducible species act as electron acceptors. Thus, the electrochemical process can be significantly affected by oxygen that adsorbs on the metal surface. Ozone, which occurs in concentrations of approximately 10 to $50 \mu \mathrm{g} \cdot \mathrm{m}^{-3}$, is particularly active, especially if $\mathrm{Al}$ is 
coated with organic substances. In the absence of an electrolyte film on the metal surface, oxygen promotes "dry atmospheric corrosion" - an extremely slow oxidation process accompanied by the formation of very thin oxide films on the surface. This process is chemical in nature and does not result in substantial metal deterioration. However, when extraneous gases are present in the atmosphere, corrosion is accelerated and often causes surface tarnishing and considerable loss of reflective and decorative properties.

Water: Water concentration is the third-largest component of the atmosphere. In contrast to the two major components, its concentration varies widely depending on geographic region. In addition, water occurs in all three states: in solid form as snow, ice. and hoar frost; in liquid form as rain, fog, dew, and melting ice or snow; and as gaseous water vapor. The water content of the atmosphere must be discussed in terms of precipitation and absolute humidity (atmospheric vapor content). Vernon ${ }^{7}$ introduced the concept of a critical relative humidity below which there would be no significant corrosion. The relative humidity is the ratio of the absolute humidity (water vapor pressure) to the saturation value and is expressed as a percentage. Many investigators have found the critical relative humidity to be a useful idea, but the critical value ranges from less than $40 \%$ In the presence of sea salt up to $80-85 \%$ when sulfur dioxide and ammonia salts are present. Also, the critical humidity decreases once corrosion starts. Desplice this variation, the critical humidity concept has become more useful since a method was developed to measure the percentage of time when this critical humidity is exceeded. 8 This period is called the time-of-wetness.

Subsequent studies $7,9-11$ have shown that the presence of liquid water on the metal surface is a requisite for the electrochemical path of the corrosion process. Liquid water is deposited on a surface not only directly by precipitation (rain, fog, melting snow), but also by adsorption and condensation. Because these processes are affected by absolute humidity and temperature, the concept of relative humidity is very important in atmospheric corrosion.

Liquid water in the atmosphere dissolves components of solid matter and gases present in the atmosphere, and consequently is a solution containing numerous species (e.g., $\left.\mathrm{SO}_{4}^{2-}, \mathrm{HCO}_{3}^{-}, \mathrm{Cl}^{-}, \mathrm{H}^{+}, \mathrm{O}_{2}, \mathrm{CO}_{2}, \mathrm{SO}_{2}\right)$. It is always saturated with oxygen $\left(\approx 8 \mathrm{~g} \cdot \mathrm{m}^{-3}\right.$, i.e., $8 \mathrm{ppm}$, at $25^{\circ} \mathrm{C}$ ) and its $\mathrm{pH}$ value can fall as low as 3 . It is obvious that precipitation occurring as fine drops (mist or fog) will contain large amounts of aggressive species from the air. Long periods of rain promote corrosion by preserving the surface electrolyte necessary for the corrosion, but may also inhibit corrosion during the subsequent period because of partial washing away of soluble species from the corroding surface.

Carbon Dioxide: The concentration of this component of the atmosphere is usually about $0.01 \%$. Although $\mathrm{CO}_{2}$ appears unimportant in atmospheric corrosion, it can influence atmospheric corrosion by decreasing the $\mathrm{pH}$ of the electrolyte. 12 
Sulfur Diaxte: This is a typical impurity found in urban and industrial atmospheres. It is emitted to the atmosphere in large amounts during combustion of sulfur-containing fuels of all types, so that the $\mathrm{SO}_{2}$ content of the alr may exceed several $\mathrm{mg} \cdot \mathrm{m}^{-3}$, 1.e.. concentrations in polluted atmospheres of $10^{-6}$ to $5 \times 10^{-4} \% .^{13}$ Sulfur dioxide is an extremely reactive gas and enhances atmospheric corrosion because upon dissolution in water, it forms sulfurous acld $\left.\mathrm{(H}_{2} \mathrm{SO}_{3}\right)$.

Hydrogen Sulfide: $\mathrm{H}_{2} \mathrm{~S}$ is another pollutant that can have significant effects on corrosion. Even when present in low concentration (it rarely exceeds $100 \mu \mathrm{g} \cdot \mathrm{m}^{-3}$ ), it promotes corrosion through formation of metal sulfides.

Other Acidic Gases: Nitric oxide occurs in urban atmospheres at concentrations up to $\approx 1 \mu \mathrm{g} \cdot \mathrm{m}^{-3}$. It is formed mainly in thunderstorms and has only a minimal effect on corrosion. 2,14

Salts: Chloride lons are chemically active components of the atmosphere, especially in coastal areas. Their concentrations decrease with distance from the coast. Maximum values in industrial atmospheres are $\approx 10$ to $30 \mu \mathrm{g} \cdot \mathrm{m}^{-3}$. Valand observed that corrosion rates depend on both oxygen and chloride contents. 15 At higher concentrations, chloride apparently reduces the adsorbed oxygen concentration and hence the corrosion rate.

In summary, the atmosphere contains numerous species whose concentrations can vary by geographic region. The concentrations of atr impurities are shown in Table 1.13

\subsection{Physical Properties of the Atmosphere Important in Corrosion}

Temperature and Its Fluctuation: Depending upon geographic region, climate variation can cause temperature extremes between -84 and $+58^{\circ} \mathrm{C}$. These extremes are of little importance in atmospheric corrosion because at low temperatures (below -5 to $0^{\circ} \mathrm{C}$ ). water usually occurs only in solid form and cannot act as an electrolyte, and the highest temperatures occur only in tropical and subtropical desert regions, where the relative humidity is too low for electrolyte layer formation. In addition, temperature affects the relative humidity. For example, when the temperature decreases, the saturation vapor pressure decreases, and hence, the relative humidity increases. Thus, low temperatures can bring relative humidity to $100 \%$ without changing the quantity of water vapor in the air. Because relative humidity and the concentrations of impirity species vary considerably, the effect of temperature on atmospheric corrosion is not well characterized.

Air Movement: Alr movement can Influence atmospheric corrosion under some conditions. It often causes rapid fluctuations in temperature and humidity and has a considerable influence on the deposition of corrosion agents onto the metal surface. In coastal areas, in particular, wind direction is important in determining the concentration profile of sait particles. ${ }^{2}$ Similarly, in industrial regions, wind promotes the transport of harmful air impurities to the metal surface. Abrasion by windborne solid particies can, 
Table 1. Concentrations of atmospheric impurities

\begin{tabular}{|c|c|c|}
\hline Species & $\begin{array}{l}\text { Normal Values for } \\
\text { Urban Atmospheres }\end{array}$ & Limiting Values \\
\hline$\overline{\infty_{2}}$ & $0.03 \%$ & $\begin{array}{l}0.306 \% \text { (caves) } \\
0.0275 \% \text { (cow shed) }\end{array}$ \\
\hline$\infty$ & $12.5 \mathrm{mg} \cdot \mathrm{m}-3$ & $29 \mathrm{mg} \cdot \mathrm{m}^{-3}$ \\
\hline $\begin{array}{l}\mathrm{pH} \text { of } \\
\text { precipitation }\end{array}$ & 5.5 & $2.9-7.2$ \\
\hline Dust & $2.3 \mathrm{mg} \cdot \mathrm{m}^{-3}$ & $\begin{array}{l}224 \mathrm{mg} \cdot \mathrm{m}^{-3} \\
\text { (cement factory) }\end{array}$ \\
\hline $\mathrm{SO}_{2}$ & $0.11-2.3 \mathrm{mg} \cdot \mathrm{m}^{-3}$ & $\begin{array}{l}10-50 \mathrm{mg} \cdot \mathrm{m}^{-3} \\
\text { (industrial area) }\end{array}$ \\
\hline $\mathrm{Cl}^{-}$ & $32 \mu \mathrm{g} \cdot \mathrm{m}^{-3}$ & $\begin{array}{l}3 \mathrm{mg} \cdot \mathrm{m}^{-3} \\
\text { (breaking surf) }\end{array}$ \\
\hline $\mathrm{O}_{3}$ & $15 \mu g \cdot m-3$ & $55 \mu g \cdot m^{-3}$ \\
\hline $\mathrm{NH}_{3}$ & $30-60 \mu \mathrm{g} \cdot \mathrm{m}^{-3}$ & $675 \mu \mathrm{g} \cdot \mathrm{m}^{-3}$ \\
\hline $\mathrm{NO}_{2}$ & $0.2-2.5 \mu \mathrm{g} \cdot \mathrm{m}^{-3}$ & $23 \mu g \cdot m^{-3}$ \\
\hline $\mathrm{H}_{2} \mathrm{~S}$ & $1 \mu g \cdot m^{-3}$ & $0.1-10 \mathrm{mg} \cdot \mathrm{m}^{-3}$ \\
\hline Formaldehyde & $5-50 \mu g \cdot m^{-3}$ & -- \\
\hline
\end{tabular}

Source: Ref. 13.

under exceptional conditions, promote corrosion by disrupting the protective layer or coating on the metal surface. Thus, the corrosivity of $\mathrm{Al}$ and its alloys is expected to vary from one place to another.

\section{General Corrosion Behavior of Aluminum}

The American Aluminum Association uses a systematic numerical system to identify wrought alloys. There are seven main alloy groups: 99.0-99.99\% $\mathrm{Al}$ (AA-1000 series); $\mathrm{Al}-\mathrm{Cu}$ alloys (AA-2000 series); Al-Mn alloys (AA-3000 series); Al-Si alloys (AA-4000 series); Al$\mathrm{Mg}$ alloys (AA-5000 series); Al-Mg-Si alloys (AA-6000 series); and Al-Zn-Mg alloys (AA7000 series). In general, $\mathrm{Al}$ alloys offer the best combination of strength and corrosion resistance compared to the nearly pure AA-1000 series. In particular, the AA-6000 series 
of Al-Mg-Si alloys have good resistance to atmospheric corrosion and are used around the world as structural alloys in many applications. Aluminum and its alloys form relatively durable oxide films that protect the metal against corrosion.

As part of a solar rellability and materlals program at Argonne National Laboratory, atmospheric corrosion of candidate batten and enclosure materials was evaluated on outdoor racks parallel to tilted solar collector panels at nine National Solar Data Network (NSDN) sites located in mild marine, mild industrial, and rural environments in eight states. 16 The corrosion behavior of AA-6061, aluminized steel (Type 2), galvanized steel, (G-90), and white-polyester-painted steel was determined by two complementary on-site experiments: (1) monitoring the telemetry from an atmospheric-corrosion sensor, a relative humidity sensor, and a temperature sensor via NSDN; and (2) determining the weight loss of relatively large (4- $\times$ 6-in.) metallic coupons and visual examination of the painted coupons that were mounted on the outdoor racks at each site over a 12-month perlod. The corrosion behavior of the three nonpainted materials adheres to the general kinetic relationship:

$$
\Delta \mathbf{W}=\mathbf{K} \mathbf{t}^{\mathbf{n}} \text {, }
$$

where $\Delta W$ is the average depth of metal loss, $K$ and $n$ are empirical constants, and $t$ is the exposure time. The values of $n$ for AA-6061 alloy and the galvanized steel were $\leq 0.2$ and $\approx 0.8$, respectively, which reflect the more protective nature of the corrosion-product film on the Al alloy. The average depth of metal loss for the AA-6061 alloy at most of the sites was $\approx 0.3 \mu \mathrm{m}$ after a $1-y r$ exposure, which is indicative of good general corrosion resistance. 16 However, the corrosion characteristics of small local regions, corresponding to intrinsic flaws or markings imbedded in the surface, are of greater concern in assessing the viability of the intrinsic-surface tag concept. Consequently, pitting is the dominant mode of corrosion that can disrupt the surface topography.

\section{Mechanism and Kinetics of Pitting Corrosion}

\subsection{Mechanism}

Pitting corrosion typically occurs in passive metals and alloys at the sites of microstructural irregularities, 1.e., impurity-rich regions, scratch lines, and other surface defects, that provide initiation sites (in contrast to chemically homogeneous surfaces), 17,18 In practice, most pitting is associated with halide lons, e.g., chloride, but this is not a necessary condition. At the point of initiation, corrosion occurs at the local anodes, whlle the local cathode is the immediately surrounding metal surface. The anodic reaction is the formation of metal ions and the release of electrons into the metal:

$$
\mathrm{M} \Rightarrow \mathrm{M}^{+}+\mathrm{e}^{-} \text {. }
$$


If the metal forms an insoluble hydroxide or a soluble (but only partly dissociated) hydroxide, there is a depletion of hydroxyl lons in the vicinity of the anode and the area tends to become acidic:

$$
\mathrm{M}^{+}+\mathrm{H}^{+}+\mathrm{OH}^{--} \Rightarrow \mathrm{MOH}+\mathrm{H}^{+} .
$$

Development of acidity within pits has been reported by many workers, and pH values as low as 4.5 have been found in Al pits. The acid may, in turn, lead to dissolution of the metal in the pit, with hydrogen evolution:

$$
2 \mathrm{M}+2 \mathrm{H}^{+} \Rightarrow \mathrm{H}_{2}+2 \mathrm{M}^{+}
$$

At the cathode, the main reactions are the reduction of hydrogen lons, oxygen, or metal lons:

$$
\begin{aligned}
& 2 \mathrm{H}^{+}+2 \mathrm{e}^{-} \Rightarrow \mathrm{H}_{2} \\
& \mathrm{O}_{2}+2 \mathrm{H}_{2} \mathrm{O}+4 \mathrm{e}^{-} \Rightarrow 4 \mathrm{OH}^{-} \text {(In alkaline solutions), }
\end{aligned}
$$

or

$$
\mathrm{O}_{2}+4 \mathrm{H}^{+}+4 \mathrm{e}^{-} \Rightarrow 2 \mathrm{H}_{2} \mathrm{O} \text { (in acidic solutions). }
$$

The electrochemical nature of pitting was demonstrated as early as 1938, by Mears and Brown. ${ }^{17}$ There are several causes of local cell formation in pitting: the most common are second-phase constituents, local scratches or abrasions, differential concentration or composition, and differential aeration.

Recently, Graedel19 discussed the chemical corrosion mechanisms in Al exposed to the atmosphere. To better understand the corrosion mechanisms, he listed the possible corrosion constituents. There are 80 candidate species that can form on Al surfaces: chemical families that are important in the corrosion of $\mathrm{Al}$ and its alloys are discussed briefly in the paragraphs below.

Adsorbed Water: Atmospheric corrosion of $\mathrm{Al}$ and its alloys is strongly influenced by the moisture content of the atmosphere. The amount of moisture adsorbed onto an aluminum oxide surface varies with relative humidity. Even in moderately humid atmospheres, more than 10 monolayers of water are present on or within the Al surface layer. 19 This amount of water is sufficient to fill the surface micropores and provide a medium for the mobilization of $\mathrm{Al}$ cations and anions and for pitting corrosion.

Oxides and Hydroxides: Upon exposure to atmosphere, alumina is the first component to form. After a few months, the oxide becomes covered by a thin layer of several hydroxides such as boehmite $\left(\mathrm{Al}_{2} \mathrm{O}_{3} \cdot \mathrm{H}_{2} \mathrm{O}\right)$ and bayente $\left(\mathrm{Al}_{2} \mathrm{O}_{3} \cdot 3 \mathrm{H}_{2} \mathrm{O}\right)$ and several variants of these compounds. ${ }^{19}$ Figure 1 shows the potential-pH diagram ${ }^{19-21}$ for the Al$\mathrm{H}_{2} \mathrm{O}$ system at $25^{\circ} \mathrm{C}$. Bayerite is stable over a wider range of acidities; complete dissolution of the oxide occurs at a $\mathrm{pH}$ of $<2.4$ in the simple $\mathrm{Al}-\mathrm{H}_{2} \mathrm{O}$ system. However, experimental 
observations have shown that some dissolution begins at a pH of 4.22 Surface pits that form on $\mathrm{Al}$ in rains and fogs have even lower acidities, and surface degradation is of the pitting type. 23

Sulfates: Sulfate lons are known to be incorporated 21 into the corroding layers of $\mathrm{Al}$. Sulfate forms from $\mathrm{SO}_{2}$ in the atmosphere and dissolves in the aqueous film on $\mathrm{Al}$ to form bisulfite ions, which are readily converted to sulfate ions by ozone or $\mathrm{H}_{2} \mathrm{O}_{2}$. Reaction with Al results in the formation of aluminum hydroxysulfates.

Chlorides: A significant cause of Al surface degradation upon exposure to marine environments is the chloride ion. 4 However, no specific compound that contains both chlorine and $\mathrm{Al}$ has been identified on $\mathrm{Al}$ surfaces exposed to outdoor atmospheres. Chlorides in the presence of sulfates are known to enhance the pitting rate by a nonuniform adsorption process.

Carbonates, Nitrates, and Organtc Compounds: These species present in the atmosphere seem to play a minor role in Al degradation.

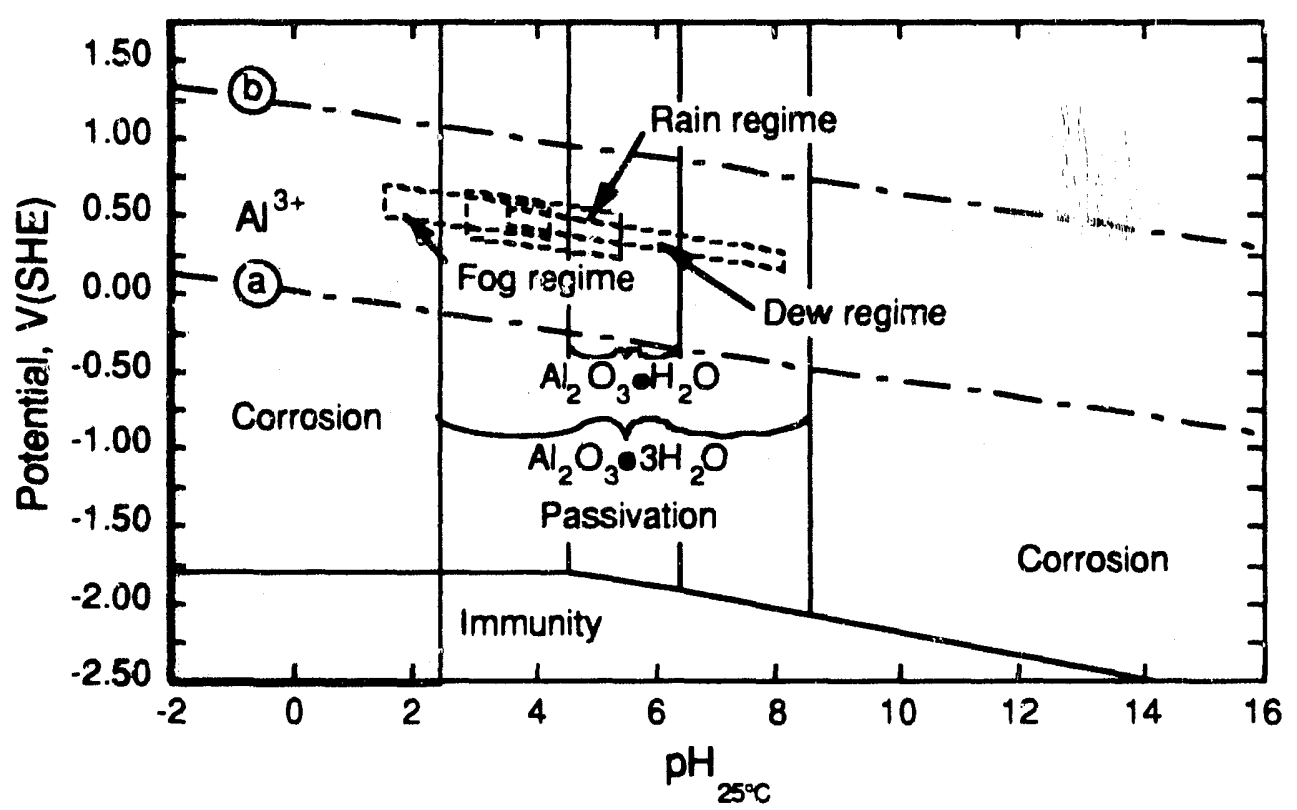

Fg. 1. Potential-pH diagram for the $\mathrm{Al}-\mathrm{H}_{2} \mathrm{O}$ system at $25^{\circ} \mathrm{C}$, for concentration of Al spectes of $0.1 \mathrm{M}$. Appraxtmate regimes for fog, rain, and dew are indicated (adapted from Refs. 19-21). Lines (a) and (b) denote the reduction of $\mathrm{H}^{+}$tons to gaseous hydrogen and the axidation of water to gaseous axygen, respectively, when partial pressure of hydrogen or oxygen is 1 atm at $25^{\circ} \mathrm{C}$. The region between the two lines is the domain of the thermodynamic stability of water under a pressure of $1 \mathrm{~atm}$. 
Pitting Potential: The pitting potential $\mathrm{E}_{\mathrm{plt}}$ is often used to describe the severity of pitting corrosion; i.e., it characterizes the resistance of metals to pitting corrosion: therefore $E_{p i t}$ can be considered as a measure of the susceptibility of different metals and alloys to pitting in corrosive environments. Below $E_{\text {pit. }}$ 1.e., at more negative potentials, the metal is in a passive state; above $E_{\text {pit. }}$ pitting corrosion occurs. Based on the vast laboratory data on critical pitting potential of $\mathrm{Al}$ alloys, pits initiate at $\mathrm{E}>-0.50 \mathrm{~V}$ on the standard hydrogen electrode (SHE) scale. Attempts have been made to use the pitting potential as a criterion for the pitting susceptibility of different $\mathrm{Al}$ alloys, but have not been successful.

\subsection{Corrosion Kinetics}

The corrosion of $\mathrm{Al}$ and its alloys has been extenstvely studied. Upon exposure to the atmosphere. Al rapidly forms a thin (protective) film of aluminum oxide. Under continued exposure, this film grows and may be transformed into various other atmospheric corrosion products. Aluminum alloys undergo mild surface roughening due to shallow pitting: there is no general thinning of the metal. Thus, maximum depth of penetration is a more meaningful measure of the extent of corrosion t'ian is weight loss (which is, however, a measure of the amount of roughening). Corrosion ates for outdoor atmospheric exposure in different environments have been reported: 24,25

$$
\begin{array}{ll}
\text { Rural } & 0.0-0.1 \mu \mathrm{m} / \mathrm{yr} \\
\text { Urban } & 1 \mu \mathrm{m} / \mathrm{yr} \\
\text { Marine } & 0.4-0.6 \mu \mathrm{m} / \mathrm{yr} .
\end{array}
$$

These values are consisient with the atmospheric corrosion results discussed previously for the AA-6061 alloy in the ANL study. ${ }^{16}$ That is, in rural atmospheres, corrosion of Al is hardly detectable, while in marine atmospheres, general corrosion resistance is still good. A compilation of corrosion data for $\mathrm{Al}$ alloys in a variety of environments is beyond the scope of this report. Although the data generally suggest that the corrosion rates are low, they may be sufficient to obscure surface topographic features, and hence surface protection is required for tag applications (this subject is discussed in Section 6).

In laboratory pitting tests, a plot of maximum pit depth versus time follows a cuberoot law, 1.e.,

$$
\mathrm{d}=\mathrm{Kt}^{1 / 3}
$$

where $d=$ maximum pit depth, $t=$ time, and $K=$ constant, depending on the alloy and the environment. Depths of pits in Al exposed to the atmosphere increase slowly with time, but the rate equation for this case has not been established.

\subsection{Size of Surface Topological Features in Relation to Corrosion Penetration}

Surface topological features, i.e., surface roughness characteristics, can influence fatigue crack initiation, 26.27 and thus are important in assessing the service life of structural 
components subjected to fatigue loading. Consequently, studies of the fatigue behavior of metals in various environments can provide quantitative characterization of surface roughness in terms of the average and maximum depth of surface grooves, the interval between peaks or valleys (average wavelength), and the sharpness or degree of curvature of the "hills" and "valleys." For example, these geometrical parameters have been determined for surfaces produced by grinding Type 304 stainless steel fatigue specimens with siliccn carbide paper of several grit sizes $(50,240$, and 600).28,29 The average depth of the surface grooves was $\approx 2.8,0.4$ and $0.03 \mu \mathrm{m}$, respectively. Surface roughness of the Al alloy specimens was similar to that of stainless steel. 30 SEM micrographs of the surfaces 28 suggest that the finer (but shallower) topological features produced by the 600-grit paper may be more useful for tags.

A comparison of the average depth of the grooves produced by silicon carbide paper of several grit sizes with the average metal loss of Al under various atmospheric corrosion conditions $(\approx 0.3 \mu \mathrm{m}$ after $1 \mathrm{yr})$ indicates that the fine $0.03-\mu \mathrm{m}$-deep grooves $(600-\mathrm{grit}$ paper) would be completely obscured by corrosion (1.e., metal loss). The average metal loss after one year is approximately the same magnitude as the grooves produced by 240-grit paper $(=0.3$ versus $0.4 \mu \mathrm{m}$. respectively), and corrosion would tend to diminish the resolution of the surface topography to a considerable extent. For deeper sciatches (50grit paper), the number of natural references within the viewing area (tag area) decreases considerably, although their depths are considerably greater (by a factor of 10) than the average metal loss by corrosion $(\approx 2.8$ vers $: s .3 \mu \mathrm{m}$, respectively).

\section{Surface Protection Methods}

Various schernes for protecting the surfaces of metals and alloys have been described in detail by Barton, ${ }^{2}$ and only the essential principles underlying the various protection schemes are described here. Because atmospheric corrosion is predominantly the result of electrochemical effects of reactive atmospheric components on the metal, several methods of protection are available.

\subsection{Mitigation of Atmospheric Corrosion}

Atmospheric corrosion is caused by the three components of the environment (atmospheric oxygen, water [liquid or vapor], and facilitating species acting simultaneously. and in certain minimum amounts). In many cases, $h$ is necessary to remove only one of these dominant factors from the atmosphere or to maintain it below the minimum concentration required for its action in order to preclude significant corrosion. However, difficulties arise in devising practical methods for such removal. 


\subsection{Corrosion Inhibitors for Protection}

Application of inhibitors to the metal surfaces can protect against atmospheric corrosion by maintaining or enhancing the inherent protective $\mathrm{Al}_{2} \mathrm{O}_{3}$ layer that forms very rapidly on the metal. The electrolyte formed by condensation of atmospheric species has an approximate neutral $\mathrm{pH}(\approx 7)$, where $\mathrm{pH}=-\log \left[\mathrm{H}^{+}\right], \log$ is logarithm to base 10 , and $\left[\mathrm{H}^{+}\right]$ is the hydrogen ion concentration in moles per liter. Therefore, the choice of sultable inhibiting species is limited to those groups of species found to reduce the aggressiveness of neutral solutions. Inhibitors that reduce the rate of the anodic reaction are termed anodic inhibitors (e.g., chromates), whereas those that slow cathodic reactions are termed cathodic inhibitors (e.g., zinc sulfate). Anodic inhibitors are potentially less useful than cathodic inhibitors because, if the anodic inhibitors are added in insufficient amounts, they reduce the effective anode area, and, if not completely effective, they lead to a much higher anodic current density (and thus greater corrosion) at remaining anodic sites. 24 Phosphates, silicates, nitrates, fluorides, benzoates, soluble olls, and certain other chemicals have been recommended, alone or in combination, to inhibit the pitting of $\mathrm{Al}$ in water.

\subsection{Protective Coatings}

\subsubsection{Organic}

Paint is usually applied to $\mathrm{Al}$ and its alloys for esthetic reasons rather than for corrosion prevention. However, Al can be coated easily and the coating is durable. Complete removal of oll and grease is essential before the coating is applied. Exposure of $\mathrm{Al}$ and Al-base alloys to chlorinated and hydroxylated solvents must be avoided because of rapid chemical reaction. 31 A so-called "wash primer," which contains chromate compounds and phosphoric acid, has been found to have excellent adhesion and is recommended for high-quality jobs. Aluminum can also be coated on a continuous line with enamels followed by baking. The popular saked enamels are vinyls and acrylics. As the paints age (weather), they suffer some deterioration and change in appearance. The two main types of change are chalking and fading. Chalking is the formation of a soft surface layer of partially deteriorated paint vehicle. Fading is caused by the action of ultraviolet light on the pigment in the paint. Protection by clear lacquers gives the longest life, ${ }^{32}$ but periodic relacquering (every several years) would be still be required.

\subsubsection{Inorganic}

Conversion Coatings: The thin oxide film on the Al surface can be thickened (by a factor of 500 to about 1-2 $\mu \mathrm{m}$ ) by swabbing with or immersion in various hot acid and alkaline solutions. The films produced are mainly $\mathrm{Al}_{2} \mathrm{O}_{3}$, but contain chemicals from the bath that render th.em more corrosion-rf sistant. 
Anodic Coatings: Much thicker $(70-250 \mu \mathrm{m})$ oxide films, which possess excellent resistance to weathering, can be produced by electrochemical treatment in certain solutions. The most common electrolyte used to anodize $\mathrm{Al}$ is sulfuric acid $(\approx 15 \%$ concentration). The anodic films can be colored by dyes or pigments. Coloring does not affect the corrosion resistance of the films. The properties of an anodic film depend on the electrolyte and on the conditions during formation (temperature, current density). Detalls of these processes are beyond the scope of this report.

Porcelain-Enamel Coatings: Porcelain enamels provide a durable decorative surface for $\mathrm{Al}$ that is to be exposed to the weather. Advantages include no oxidation at chips and edges, and, in addition, a greater flexibility and lower susceptibllity to chipping. The durability of some enamels to the weather is superior to that of others, from the standpoint of resistance to fading and freedom from spalling. This process has been extensively applied to AA-6061 alloy.

\subsubsection{Motallic}

The Idea of laying a corrosion-resistant metal over a less-resistant one to improve the resistance of the latter is the basis of one of the oldest methods of protection against corrosion. It is also possible to apply a surface layer of less-noble alloy to Al by processes such as spray-metallizing to obtain protection. For example, alloy AA-7072 is used to coat $\mathrm{Al}-\mathrm{Mg}-\mathrm{SI}$ alloys such as AA-6061 and the stronger alloys of the AA-7075 class. The corrosion protection properties depend on both the type of metal used as a coating and the coating techrique.

\subsection{Cathodic Protection}

Alclad $\mathrm{Al}$, which is a duplex product consisting of a thin layer of one alloy integrally bonded to the core, is avallable in sheet and tubing. The cladding is chosen to be anodic to the core, so that the product possesses built-in cathodic protection. Use of $\mathrm{Al}-\mathrm{Zn}$ claddings to protect alloys AA-1200, AA-3003, and AA-6061 has been found effective in preventing perforation by pitting in corrosive environments.

\section{Tag Protection Method}

Atmospheric corrosion of an unprotected Al-alloy tag surface would obscure micrometer-scale features relied upon for authentication. Therefore, it is necessary to protect surfaces from the open environment in order to retain the features essential for tag verification. Any protection method must also provide TLI functionality, nonintrusive application, and multiple field examination capabtlity. Section 5 of this report discussed several corrosion protection methods. Obviously, some of these methods are not practical for tag protection. For example, covering the tag surface with a porcelain coating can be ruled out because it is intrusive to apply and not removable for field inspection. 
The recommended surface-protection method is to place an adhesively bonded Al-alloy label over the tag area. This protective label reduces migration of atmospheric water and corrosive electrolytes onto the fingerprinted surface. Migration of corrosion constituents is attenuated because they are required to travel a long distance through the adhesive. This label would also have a bar code for TLI inventory. It should be emphastzed that atmospheric corrosion testing, as discussed in the Appendix, must be performed to confirm the corrosion protection offered by the label.

Three other surface-protection methods can be employed to provide increased corrosion resistance:

- Increasing the thickness of the protective oxide coating by applying a conversion coating to the fingerprinted surface. Conversion coatings are discussed in Section 5 .

- Interception of any water that migrates through the adhesive by absorption in a desiccant rather than on the tagged surface. Electrolytic corrosion cannot proceed without the presence of water. The desiccant would be incorporated in a cavity of the bar code label.

- In especially severe environments, the Al-alloy protective label could be porcelain-enameled to ensure its integrity.

Of course, these additional protection methods must be subjected to corrosion testing, as discussed in the Appendix, to confirm their effectiveness.

\section{Summary}

Atmospheric corrosion of $\mathrm{Al}$ and its alloys is an extremely slow process. Upon exposure of $\mathrm{Al}$ and its alloys to natural environments, a thin protective oxide forms rapidly and the metal becomes passive. Consequently, $\mathrm{Al}$ and its alloys become susceptible to localized corrosion (pitting), especially in the presence of water and impurities such as chlorides. Initial stages of corrosion generally produce discoloration, roughening, and pitting (depending on the severity of environments) that can destroy shallow surface topographic features that have been proposed for tagging.

Various protection schemes are outlined to protect the protective oxide from disruptive agents such as water and impurities. Some of the methods to reduce the aggressiveness of the atmosphere are not considered practical in the tagging of military equipment such as tanks and missiles.

Experiments for investigating corrosion in natural environments will lead to a range of results. Extremely slow rates of corrosion compel one to resort to accelerated laboratory tests. The problems in simulating atmospheric environments without altering the 
corrosion paths, which can change the corrosion products and corrosion mechanisms, are formidable, and accelerated testing can lead to spurious results.

On the basis of the preceding comments, a tagging system that relies on the intrinsic-surface topography of a metal/corrosion product surface requires protection against natural environments. If these surfaces are not protected, they may be subject to unintentional human intervention, 1.e.. cleaning, abrasion, painting, that could render the tag useless for its intended purpose. A method of protecting intrinsic-surface tags has been proposed. 


\section{Appendix: Experimental Methods for Investigating Atmospheric Corrosion}

The multiplicity of the atmosphere's corrosion-promoting properties that are due to climate and the effects of civilization, and the resulting many-faceted aggressiveness to metallic products, make the design and organization of authortative test methods very difficult. Care must be exercised in deciding on the types of experiments and which environmental conditions to look for in choosing exposure sites. ${ }^{2}$ The choice of naturalatmosphere or laboratory experiments depends on the specific detalls avallable for the environments and the purpose of such experiments. Natural tests are frequently the only reliable basis for comparing different protection methods. But the relatively slow rate of natural corrosion requires several years for comparative tests to be performed under natural conditions.

\section{A.1 Testing in Natural Atmospheres}

The choice of test sites depends on the aim of the test. For example, to estimate corrosion in marine atmospheres, a test site is established on the seashore, with provision for test racks to be sited at different distances from the waterline. In urban and industrial atmospheres, selection of typical environmental conditions is often difficult. As in marine experiments, the aggressiveness of the atmosphere can change significantly within a distance of a few meters due to action of air pollutants. To obtain meaningful test results, it is necessary to obtain meteorological/chemical characterization of test sites, as was done in the ANL study. ${ }^{16}$ Because the atmospheric corrosion of metals occurs only in the presence of a surface electrolyte, the meteorological measurements should indicate the duration of presence of water or time of wetting.

As discussed previously, liquid water may be present on the surface from three sources: precipitation (rain, falling mist, melting snow), dew (when the dew point is exceeded), or conversion of water vapor into liquid water during a sorption process (when the so-called critical relative humidity is exceeded). All of these processes can be defined by meteorological measurements. If the parameters are measured sufficiently often, or continuously (with a thermohydrograph), the time of wetting by a surface layer of water, and hence the duration of active corrosion, can be determined. Empirical, site-specific equations have been developed for the time of wetness. 6 These empirical relations. however, do not greatly assist the understanding of corrosion processes. Direct evaluation of continuous records of temperature and relative humidity can give simllar results. The duration of surface wetting may also be determined directly; special macrocells have been developed, and with an appropriate electrode system, the corrosion current in the presence of dew can be measured and evaluated.

Temperature measurements are important for estimating atmospheric corrosion. Annual, monthly, or even dally average values are insufficient. Temperature measurements should be made at the shortest practical intervals. 
Alr pollutants and other corrosion facilitators are additional parameters that must be characterized at test sites. There is a clear connection between incremental corrosion and the total amounts of the species that contact a specified geometric surface. The concentrations of the facilitators can therefore be determined by simple adsorption methods and expressed in terms of weight per unit area per unit time.

In quantitative assessments of corrosion experiments, measurements of weight loss are widespread, simple, and useful. The weight loss can be converted to corroston rates. In the early stages of atmospheric corrosion of $\mathrm{Al}$ and its alloys, dimples, corrosion scars, and other irregularities may be observed. Mechanical or optical profile measurements (which resemble roughness measurements) can provicie information on corrosion uniformity. Corrosion scars or pits can be described by their number per unit area, by their depth, and by statistical methods. It is also necessary to examine the corrosion products by conventional methods such as X-ray or electron diffraction and metallography. At times, measurements of optical properties of the surface may be used to monitor the progress of corrosion in the atmosphere. In general, it is difficult to select a single best quantitative method for assessing corrosion.

\section{A.2 Testing in the Laboratory}

The long periods and high expense associated with testing in natural atmospheres make it desirable to use less expensive laboratory tests. Testing in the laboratory allows the use of rigorously defined cond.tions and cyclic changes of the conditions (for example. cyclic dry/wet conditions), if desired. Several accelerated tests are currently used, including salt spray, condensation apparatus, artificial industrial atmospheres, and $\mathbf{S O}_{2}$. A closer examination of some of these tests shows that they have only limited (or no) comparability to conditions in natural atmospheric corrosion. The results of such tests should therefore be regarded as only approximate information.

As discussed earlier, atmospheric corrosion is a discontinuous process that alternately proceeds and stops. Reaction rates during individual corrosion periods can thus be defined as functions of climatic factors or related factors. The overall corrosion is related to the total of the "activen intervals. Therefore, it should be possible to increase the frequency or length of these periods relative to those occurring naturally, or even to allow the corrosion to proceed uninterrupted.

The second method of accelerating the corrosion process is to utilize the dependence of atmospheric corrosion kinetics on climatic parameters that can be adjusted in the laboratory, i.e., the environments can be made more severe, for example, by increasing the temperature. Enhancement of water activity is also easily obtained. Water can be allowed to condense in a chamber or the humidity can be adjusted. However, the reaction paths by which various species accelerate corrosion reactions in nature are complicated, and individual steps in the conversion reactions cannot be neglected. If for example, $\mathrm{SO}_{2}$ action is enhanced, the limiting value for acceleration is probably related to the rapid conversion of the sulfur dioxide on the surface to sulfate. If, the $\mathrm{SO}_{2}$ content 
exceeds a certain concentration, $\mathrm{SO}_{2}$ begins to react as a solution species (1.e., $\mathrm{HSO}_{3}^{-}$) and this leads to corrosion reactions that differ markedly from the natural ones. Enhanced dosing with chloride is also beset by similar difficulties. Significant increases in temperature over those found during active corrosion periods in nature can also alter the mechanisms.

Similarly, it is difficult to develop accelerated atmospheric testing of coatings if the degradation mechanism of these systems is not understood. The problems are particularly important for organic coatings because the compatibility of coatings with water, as well as thermal aging, must be taken into account.

These limitations for accelerating atmospheric tests suggest that satisfactory acceleration of atmospheric corrosion in the laboratory is not a solved problem. No generally applicable test exists. Instead, each test requires special consideration and appropriate conditions and assessment procedures. If accelerated tests are used, care should be taken to ensure that the corrosion mechanism does not change due to acceleration of the corrosion process and to interpretation of results where laboratory corrosion rates are related to those in the atmosphere. 
1. R. G. Palm, Argonne National Laboratory, unpublished information (Jan, 1989).

2. K. Barton, Protection Agctinst Atmospheric Corroston, John Wiley \& Sons, New York (1976).

3. I. L. Rozenfield, Atmospheric Corroston of Metals, NACE, Houston, TX (1972).

4. R. T. Foley, Corrosion, Vol. 42, No. 5, p. 277 (1986).

5. Atmospheric Corrosion of Metals, ASTM STP 767, S. W. Dean and E. C. Rhea, eds., American Society for Testing and Materials, Phlladelphia, PA (1982).

6. G. A. Sussex, J. D. Scantlebury, and J. B. Johnson, "Atmospheric Corrosion and its Accelerated Testing," in International Congress on Metallic Corrosion, Toronto, National Research Councll Canada, Vol. 3, p. 192 (1984).

7. W. H. J. Vernon, Trans. Farad, Soc., Vol, 27, p. 255 (1931).

8. P. J. Sereda, "Measurement of Surface Molsture and Sulfur Dioxide Activity at Corrosion Sites," ASTM Bulletin No. 246 (May 1960) American Soclety for Testing and Materials, Philadelphia, PA, p. 47.

9. P. J. Sereda, Industrial and Engineering Chemistry, Vol. 52, No. 2, p. 157 (Feb. 1960).

10. H. Guttman and P. J. Sereda, in Metal Corrosion in the Atmosphere, ASTM STP 435. American Soclety for Testing and Materials, Philadelphia, PA (1968), p. 326.

11. H. Guttman, in Metal Corrosion in the Atmosphere, ASTM STP 435, American Soclety for Testing and Materials, Philadelphia, PA (1968), p. 223.

12. H. Kaesche, Werkstoffe und Korrosion, Vol. 15, p. 379 (196\%).

13. A. Kutzelnigg, Werkstoffe und Korrosion, Vol, 8, p. 492 (1957).

14. F. M. Clark, Electr. Engng., p. 671 (1937).

15. T. Valand, Corros. Sclence, Vol, 11, p. 197 (1971).

16. C. F. Cheng, Final Report: Atmospheric Corrosion of Batten and Enclosure Materials for Flat-Plate Solar Collectors, Argonne National Laboratory Report ANL-83-30 (April 1983).

17. R. B. Mears and R. H. Brown. Transactions Electrochem. Soc., Vol, 75, p. 495 (1938).

18. Z. Szklarska-Smialowska, Pttting Corrosion of Metals, NACE, Houston, TX, p. 95 (1986).

19. T. E. Graedel, J. Electrochem. Soc., Vol. 136, No. 4, p. 204C (1989).

20. T, E. Graedel, J. Electrochem. Soc., Vol, 133, p. 2476 (1986). 
21. E. Mattsson, Chemtech., Vol. 15, p. 234 (1985).

22. A. Berzins, J. V. Evans, and R. T. Lowson, Aust, J. Chem., Vol. 30, p. 721 (1977).

23. H. Kaesche, in Passivtty of Metals, R. P. Frankenthal and J. P. Kruger, eds, The Electrochemical Society, Inc., Princeton, NJ, p. 935 (1978).

24. H. P. Godard, W. B. Jepson, M. R. Bothwell, and R. L. Kanc. The Corrosion of Light Metals, John Wiley \& Sons, Inc., New York (1967).

25. M. Lashermes, A. Gullhaudis, M. Reboul, and G. Trentelivres, in Aimospheric Corrosion, W. H. Allor, ed., Wiley-Intersclence, New York, p. 353 (1982).

26. J. C. Grosskreutz and D. K. Benson, Surfaces and Interfaces II, J. J. Burke, N. L. Reed, and V. Weiss, eds., syracuse University Press, Syracuse, NX, p. 61 (1966).

27. A. S. Argon, Corroston Fatigue, O. F. Devereaux, A. J. McEivily, and R. W. Staehle, eds., p. 176, NACE (1.972),

28. P. S. Malya and D. E. Busch, Effect of Surface Roughness on Low-Cycle Fatigue Behavior of 'Type 304 Stainless Steel, Met. Trans. Vol, 6A, 1761-1766 (1975).

29. P. S, Malya, Geometrical Characterization of Surface Roughness and its Application to Fatigue Crack Initiation, Mater. Sc1. \& Eng., Vol. 21, 57-62 (1975).

30. E. Siebel and M. Gaier, The Influence of Surface Roughness on the Fatigue Strength of Steels and Non-Ferrous Alloys, VDI Zeltschrift, Vol. 98, No. 30, p. 1715 (1956); reprinted, in part, in The Engineers Digest, Vol, 18, No. 3, p. 109 (1957).

31. C. P. Dillon, Aluminum in Potentially Corrosive Organic Solvents, Materials Performance, Vol. 29, No, 11, p. 51 (1990).

32. R. D. Guminski and F. M. P. Meredith, Trans, Inst, Met. Fin., Vol, 40, p. 35 (1963). 


\section{Distribution for ANL/ACTV-91/6}

Internal

R. Boyar

P. Malya (6)

C. Malefyt (2)

R. Palm (20)

A. Phillipedes

R. Poeppel

A. C. Raptis

N. Sather

W. Shack

C. E. Till
A. Travelli (3)
R. Weeks
T. Wolsko
N. Zaluzec

ANL Patent Dept.

ANL Contract File

TIS File (3)

RE File: 54920, A15

\section{External}

DOE/OSTI (12)

Manager, Chicago Operations, DOE

ANL Libraries (2)

Materials and Components Technology Division Review Committee:

H. Berger, Industrial Quality Inc., Gaithersburg, MD

M. S. Dresselhaus, Massachusetts Institute of Technology, Cambridge, MA

S. J. Green, Electric Power Research institute, Palo Alto, CA

R. A. Greenkorn, Purdue University, West Lafayette, IN

C. - Y, LI, Cornell Untversity, Ithaca, NY

P. G. Shewmon, Ohlo State Untversity, Columbus

R. Smith, EPRI NDE Center, Charlotte, NC

U.S. Dept. of Energy, Washington, DC

V. Alessi

R. Bowen

A. Czajkowski

J. Fuller (7)

M. Koontz

Center for Verification Research, Newington, VA

J. Anthony

R. Desjardins

Defense Nuclear Agency, Alexandria, VA

M. Evenson

Idaho National Engineering Laboratory

F. Tsang

Los Alamos National Laboratory

C. Mansfield 

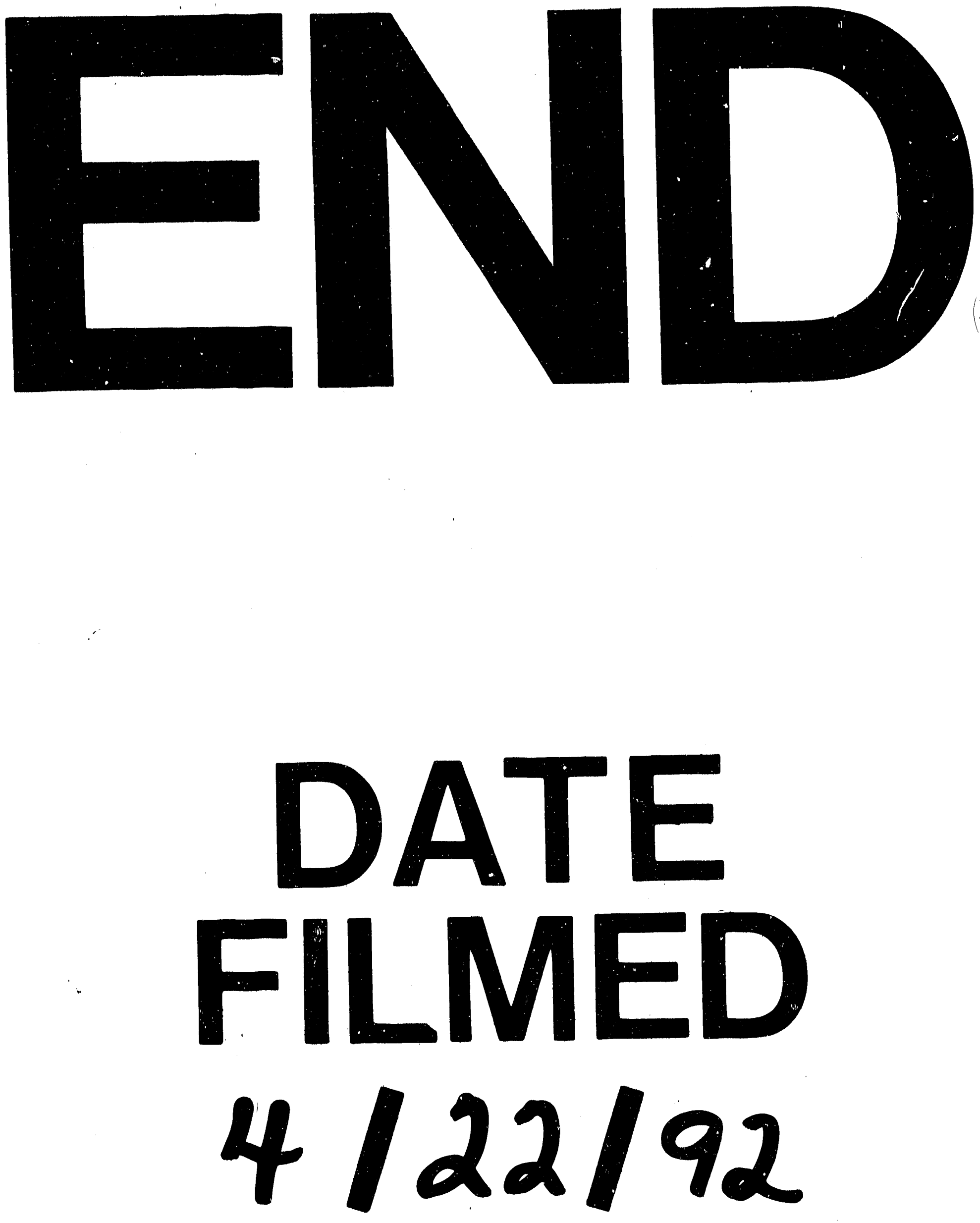